\title{
The retrospective analysis of urinary tract infection in renal transplant recipients
}

\author{
Ender Eren ÖZÇELİK ${ }^{1}$, Alparslan ERSOY² \\ ${ }^{1}$ Bursa Uludağ University Faculty of Medicine, Department of Internal Medicine, Bursa, Turkey \\ ${ }^{2}$ Bursa Uludağ University Faculty of Medicine, Division of Nephrology, Bursa, Turkey
}

Turk J Int Med 2021;3(Supplement 1):S14-S16

DOI: $\underline{10.46310 / \text { tjim. } 872047}$

Keywords: Kidney transplant, complication, urinary tract infection

Infection is the most common reason for admission to the emergency department in the early period after transplantation. Urinary tract infections (UTIs) in adult kidney transplant patients are common. Their incidence is significantly higher than in the general population. ${ }^{1}$ The majority of sepsis cases in this period are composed of UTIs. ${ }^{2}$ While mild UTIs generally do not affect graft function, acute pyelonephritis observed in the post-transplant period causes a decrease in graft function and an increase in mortality. ${ }^{3}$ In the literature, a small amount of data has been published regarding the incidence, epidemiological features, and risk factors of UTIs in kidney transplant recipients. In this retrospective study, we evaluated the data of 550 patients who underwent kidney transplantation between January 2006 and May 2019 at our center and analyzed UTIs' characteristics.

Among 550 recipients, 633 episodes were detected in 200 patients (36.4\%). Recurrent infection was encountered in 74 (37\%) of 200 patients. We determined 1 episode in 63 (31.5\%), 2 episodes in 39 (19.5\%), 3 episodes in $31(15.5 \%), 4$ episodes in $14(7 \%), 5$ episodes in $10(5 \%), 6$ episodes in $8(4 \%)$, and 7 or more episodes in $35(17.5 \%)$. While $48.3 \%(n=306)$ of 633 episodes were asymptomatic bacteriuria, $51.6 \%(n=327)$ was symptomatic. The risk factors for UTI were female gender, the advanced age of transplant and advanced donor age, longterm dialysis period before transplant, prolonged urinary catheterization and hospitalization time after transplant, cytomegalovirus infection, vesicoureteral reflux, and neurogenic bladder history. At the survival analysis, a transplant from living donor, female gender, use of tacrolimus, mycophenolate mofetil and corticosteroid combination as maintenance immunosuppressive therapy, preemptive transplant compared to

Received:February 01,2021;Accepted:March 3,2021; Published Online:March 6, 2021 
patients receiving peritoneal dialysis was found to be associated with longer survival; advanced age of transplant, obesity, delayed graft function, acute rejection, diabetes mellitus and a history of cytomegalovirus infection was also associated with a shorter life span. Escherichia coli (64.9\%) and Klebsiella pneumonia (51.6\%) were the most common causative microorganisms, and ESBL (Expanded Spectrum Beta-Lactamase) was positive in $19.9 \%$ and $67.5 \%$ of them, respectively.

Similarly, female gender, the advanced age of transplant, prolonged catheterization time, history of vesicoureteral reflux, neurogenic bladder, acute rejection, and deceased donor were dependent risk factors for developing of UTI in transplant recipients in other studies, ${ }^{4-6}$ but not body mass index, history of diabetes mellitus, dialysis type and duration, primary kidney disease, donor type, delayed graft function, and history of acute rejection in another study. ${ }^{7}$ UTI frequency in the female gender increases due to anatomical differences such as the shorter urethra compared to men and its relative proximity to the perianal region and vulva, as in the general population. Age-related changes in the urinary tract and existing additional diseases are important factors that predispose to bacterial colonization. Prolonged urinary catheterization and hospitalization durations facilitate pathogen entry into sterile body parts in the postoperative period. Immunosuppression, frequent hospitalizations, and surgical interventions increase the risk of nosocomial infections in dialysis patients. A history of vesicoureteral reflux facilitating bacterial invasion and a neurogenic bladder causing urinary stasis poses a UTI risk.

Hospitalizations for septicemia are most commonly associated with UTI. ${ }^{8}$ In our cohort, antibiotics in the carbapenem group, started in more than half of the episodes. There is an increase in trimethoprim/sulfamethoxazole, ciprofloxacin and ceftazidime resistance in Klebsiella species. ${ }^{9}$ Although the microorganism spectrum in the studies is similar all world, ESBL positivity is noticeably higher than the average in UTI episodes is an observation in parallel with the increasing antibiotic resistance both in our country and in the world in recent years. This observation was considered as a cautionary finding for the review of antibiotic selection preferences in our clinic. Finally, UTIs being a threat to graft and patient survival in the post-transplant period should be treated effectively by carefully evaluating risk factors.

\section{Conflict of Interests}

Authors declare that there are none.

\section{Acknowledgment}

This study has been presented in $17^{\text {th }}$ Uludag Internal Medicine National Winter Congress, $6^{\text {th }}$ Bursa Family Medicine Association National Congress, $11^{\text {th }}$ Uludag Internal Medicine Nursing Congress, 5-7 March 2021, Bursa, Turkey.

\section{References}

1. Rice JC, Safdar N; AST Infectious Diseases Community of Practice. Urinary tract infections in solid organ transplant recipients. Am J Transplant. 2009 Dec;9 Suppl 4:S267-72. doi: 10.1111/j.1600-6143.2009.02919.x.

2. Trzeciak S, Sharer R, Piper D, Chan T, Kessler C, Dellinger RP, Pursell KJ. Infections and severe sepsis in solid-organ transplant patients admitted from a university-based ED. Am J Emerg Med. 2004 Nov;22(7):530-3. doi: 10.1016/j.ajem.2004.09.010.

3. Pellé G, Vimont S, Levy PP, Hertig A, Ouali N, Chassin C, Arlet G, Rondeau E, Vandewalle A. Acute pyelonephritis represents a risk factor impairing long-term kidney graft function. Am J Transplant. 2007 Apr;7(4):899-907. doi: 10.1111/j.16006143.2006.01700.x.

4. Chuang $\mathrm{P}$, Parikh CR, Langone A. Urinary tract infections after renal transplantation: a retrospective review at two US transplant centers. Clin Transplant. 2005 Apr;19(2):230-5. doi: 10.1111/j.13990012.2005.00327.x.

5. Wu X, Dong Y, Liu Y, Li Y, Sun Y, Wang J, Wang S. The prevalence and predictive factors of urinary tract infection in patients undergoing renal transplantation: A meta-analysis. Am J Infect Control. 2016 Nov 1;44(11):1261-8. doi: 10.1016/j.ajic.2016.04.222

6. Papasotiriou M, Savvidaki E, Kalliakmani P, Papachristou E, Marangos M, Fokaefs E, Maroulis I, Karavias D, Goumenos DS. Predisposing factors to the development of urinary tract infections in renal transplant recipients and the impact on the longterm graft function. Ren Fail. 2011;33(4):405-10. doi: 10.3109/0886022X.2011.568137.

7. Pesce F, Martino M, Fiorentino M, Rollo T, Simone S, Gallo P, Stallone G, Grandaliano G, Schena A, Margiotta M, Mininni D, Palieri R, Lucarelli G, Battaglia M, Gesualdo L, Castellano G. Recurrent urinary tract infections in kidney transplant recipients during the first-year influence long-term graft function: a single-center retrospective cohort study. J Nephrol. 2019 Aug;32(4):661-8. doi: 10.1007/s40620-019-005915 .

8. Abbott KC, Oliver JD 3rd, Hypolite I, Lepler LL, Kirk AD, Ko CW, Hawkes CA, Jones CA, Agodoa LY. Hospitalizations for bacterial septicemia after renal 
transplantation in the united states. Am J Nephrol. 2001 Mar-Apr;21(2):120-7. doi: 10.1159/000046234.

9. Korth J, Kukalla J, Rath PM, Dolff S, Krull M, Guberina H, Bienholz A, Wilde B, Becker S, Ross

$\mathrm{B}$, Anastasiou OE, Kribben A, Witzke O. Increased resistance of gram-negative urinary pathogens after kidney transplantation. BMC Nephrol. 2017 May 19;18(1):164. doi: 10.1186/s12882-017-0580-z. 